\title{
Divergência genética entre progênies de pupunheira quanto a caracteres de palmito
}

\author{
Jacson Rondinelli da Silva Negreiros(1), Celso Luis Bergo(1), \\ Daniela Popim Miqueloni ${ }^{(1)}$ e Aureny Maria Pereira Lunz ${ }^{(1)}$
}

(1)Embrapa Acre, Rodovia BR364, Km 14, CEP 69900056 Rio Branco, AC. Email: jacson.negreiros@embrapa.br, celso.bergo@embrapa.br,
danimique@yahoo.com.br, aureny.lunz@embrapa.br

Resumo - O objetivo deste trabalho foi estimar a divergência genética de progênies de pupunheira, com base em variáveis agronômicas do palmito. O delineamento experimental em blocos ao acaso foi utilizado em látice triplo 10x10, com 100 tratamentos (progênies) e três repetições. Foram feitas as seguintes avaliações: massa da base do palmito, produtividade do palmito de primeira e de segunda qualidade, número de plantas por parcela e diâmetro do palmito. A divergência genética foi estimada pela distância generalizada de Mahalanobis, como medida de dissimilaridade, e pelo método de otimização de Tocher e variáveis canônicas, na formação de grupos. As progênies formaram 26 grupos distintos. A variância acumulada pelas três primeiras variáveis canônicas foi de $75,12 \%$. Planta por parcela e massa do palmito de segunda, indiretamente relacionada à massa do palmito de primeira, foram os caracteres mais importantes na discriminação das progênies, na primeira variável canônica $(35,77 \%)$. A massa da base do palmito apresentou relação indireta com a produtividade do palmito de segunda e plantas por parcela, na segunda variável canônica $(22.93 \%)$, e com a massa do palmito de primeira na terceira variável canônica (16,42\%). Dezessete progênies de quatro grupos divergentes (G3, G5, G11 e G12) têm potencial para seleção quanto à produtividade de palmito no programa de melhoramento da pupunheira.

Termos para indexação: Bactris gasipaes, agrupamento, análise multivariada, variáveis canônicas.

\section{Genetic divergence among peach palm progenies for palm heart characters}

\begin{abstract}
The objective of this work was to estimate the genetic diversity of peach palm progenies, based on palm heart agronomic traits. A randomized block design was used in 10x10 triple lattice, with 100 treatments (progenies) and three replicates. The following evaluations were made: palm heart base mass, first-rate and second-rate palm heart productivity, number of plants per plot, and palm heart diameter. The genetic divergence was estimated by generalized Mahalanobis distance, as a dissimilarity measure, and by the Tocher optimization method and canonical variables, for group formation. The progenies formed 26 groups. Cumulative variance of the first three canonical variables was $75.12 \%$. Plant per plot and second-rate palm heart mass, indirectly related to the first-rate palm heart mass, were the most important characters in the discrimination of progenies, in the first canonical variable (35.77\%). Mass of the palm heart base was indirectly related to the second-rate palm heart productivity and number of plants per plot, in the second canonical variable $(22.93 \%)$, and to the first-rate palm heart productivity in the third canonical variable $(16.42 \%)$. Seventeen progenies of four divergent groups (G3, G5, G11 and G12) have potential for selection as to palm heart yield in the breeding program of peach palm.
\end{abstract}

Index terms: Bactris gasipaes, clustering, multivariate analysis, canonical variables.

\section{Introdução}

A pupunheira, Bactris gasipaes Kunth, é uma planta nativa da Amazônia de grande importância econômica, tanto em nível regional como nacional. É cultivada em consórcios (sistemas agroflorestais) e em monocultivos, normalmente, para a produção de frutos e palmito, porém o cultivo para a produção de palmito desperta maior interesse entre os produtores
(Yokomizo \& Farias Neto, 2003). Além disso, é considerada a espécie com o maior potencial para produção de palmitos, em substituição à extração do palmito de espécies como açaizeiro, Euterpe oleracea Mart., e juçara, Euterpe edulis Mart. (Batagin-Piotto et al., 2012).

O Brasil é o maior produtor e consumidor de palmito do mundo, com produção anual de 103.419 toneladas, em sua maioria proveniente do açaí e juçara (Galdino 
\& Clement, 2008; Instituto Brasileiro de Geografia e Estatística, 2011).

Entre as vantagens do palmito da pupunheira, em comparação ao de outras espécies, estão a precocidade de corte, boa produtividade, bom perfilhamento, rusticidade, além do não escurecimento enzimático (Kalil Filho et al., 2010).

Há grandes divergências quanto à origem e rota de domesticação da pupunheira, o que resulta em definição não exata das variedades; distinguem-se "raças primitivas", que são formadas por indivíduos com um conjunto de características morfológicas e funcionais transmitidas por herança, e que foram criadas pelos primeiros povos da Amazônia, nos milhares de anos de domesticação (Clement, 1988; Clement \& Bovi, 2000; Araújo et al., 2010). Os plantios de pupunha para palmito no Brasil estão representados pelas populações de Yurimáguas (Peru), da raça Pampa Hermosa, e de Benjamin Constant (AM, Brasil), da raça Putumayo (macrocarpa) melhorada por duas gerações (Kalil Filho et al., 2010). Esta última, é encontrada ao longo dos rios Solimões e Amazonas, no Brasil, e em áreas adjacentes na Colômbia e Peru, e apresenta frutos grandes com muito amido (Sousa et al., 2001). Embora esta raça tenha sido originariamente domesticada para a produção de frutos para alimentação humana, suas sementes, oriundas de progênies selecionadas para a produção de palmito, têm sido utilizadas na formação de plantios comerciais de pupunha para palmito em diferentes regiões do Brasil (Clement, 1988). A seleção de tais progênies tem levado em conta caracteres, propostos por Clement (1997), como componentes de um ideótipo adequado para a produção de palmito, entre os quais pecíolo/ráquis sem espinhos, alta taxa de crescimento relativo, produção contínua de perfilhos, colheita do palmito com menos de 12 meses e palmito de bom tamanho.

Em razão dessa multiplicidade de origens e rotas de domesticação, a pupunheira apresenta grande variabilidade genética, porém, ainda pouco caracterizada (Martel et al., 2003). Esta variabilidade genética das populações de pupunheira oferece enorme potencial para o melhoramento genético, com ganhos em qualidade e produtividade (Flori et al., 2001), e a descrição de suas características morfoagronômicas possibilita a identificação de acessos divergentes (Araújo et al., 2010).
Em um programa de melhoramento genético, a população base deve apresentar variabilidade genética e valores médios quanto aos caracteres produtivos de interesse econômico a serem melhorados. A caracterização dos indivíduos ou acessos de uma população base pode ser realizada a partir das avaliações de características morfoagronômicas e da mensuração de caracteres qualitativos e quantitativos (Sudré et al., 2005). Geralmente, durante a caracterização de uma população, são avaliados vários caracteres, o que gera um grande volume de dados. Para a análise desse banco de dados, as estatísticas multivariadas são de grande utilidade e podem ser aplicadas a um conjunto de caracteres correlacionados, para a caracterização genética de uma população (Oliveira et al., 2007). Essa técnica é aplicada em diferentes áreas científicas, que incluem genética e melhoramento de espécies perenes (Oliveira et al., 2007; Ribeiro et al., 2012; Silva et al., 2012).

O objetivo deste trabalho foi estimar a divergência genética, por métodos multivariados, em progênies de meios-irmãos de pupunheiras, com base em variáveis agronômicas do palmito.

\section{Material e Métodos}

O teste de progênies foi realizado no campo experimental da Embrapa Acre, Rodovia BR364, Km 14, Rio Branco, AC, a $10^{\circ} 1{ }^{\prime} 30^{\prime \prime} \mathrm{S}, 67^{\circ} 42^{\prime} 18^{\prime \prime} \mathrm{W}$, a cerca de $160 \mathrm{~m}$ de altitude. $\mathrm{O}$ clima da região, segundo a classificação de Köppen, é do tipo Awi, quente e úmido, com temperatura máxima de $31^{\circ} \mathrm{C}$ e mínima de $21^{\circ} \mathrm{C}$, precipitação anual de $1.940 \mathrm{~mm}$ e umidade relativa de $80 \%$. O solo da área experimental foi classificado como Argissolo Vermelho distrófico alumínico (Santos et al., 2006). Os atributos químicos do solo na camada de $0,0-0,2 \mathrm{~m}$ de profundidade foram: $\mathrm{pH} \mathrm{H}_{2} 0,4,9 ; \mathrm{C}$ orgânico, 11,1 $\mathrm{g} \mathrm{kg}^{-1}$; P, 2,56 mg kg-1 $\mathrm{K}, 0,24$ cmol $_{\mathrm{c}} \mathrm{kg}^{-1}$; $\mathrm{Ca}, 2,34 \mathrm{cmol}_{\mathrm{c}} \mathrm{kg}^{-1} ; \mathrm{Mg}, 1,68 \mathrm{cmol}_{\mathrm{c}} \mathrm{kg}^{-1} ; \mathrm{A} 1$, $1,15 \mathrm{cmol}_{\mathrm{c}} \mathrm{kg}^{-1}$; CTC, 5,4 $\mathrm{cmol}_{\mathrm{c}} \mathrm{kg}^{-1}$; V, 38\%; saturação por alumínio (m), 26\%. Os conteúdos de areia, silte e argila foram 230, 420, e $350 \mathrm{~g} \mathrm{~kg}^{-1}$, respectivamente.

As sementes para a implantação do teste de 100 progênies de pupunheira foram coletadas de plantios comerciais do projeto Reca (Reflorestamento Econômico Consorciado Adensado), localizado na vila Nova Califórnia, RO. As sementes que originaram os plantios do projeto Reca são do Município de Benjamin 
Constant, AM, de populações da raça macrocarpa Putumayo. Com base nessas avaliações, as plantas foram selecionadas com os critérios ausência de espinhos na estipe e plantas vigorosas com numerosos perfilhos e entrenós maiores do que $20 \mathrm{~cm}$ a $1,2 \mathrm{~m}$ de altura do nível do solo.

O delineamento experimental em blocos ao acaso foi utilizado em látice triplo 10x10, com 100 tratamentos (progênies de meios-irmãos) e três repetições. A parcela foi constituída de oito plantas na linha, tendo sido a parcela útil constituída apenas das seis plantas centrais. O experimento foi conduzido em espaçamento de 2,0x1,0 m, sem irrigação, com os tratos culturais recomendados para a cultura da pupunha (Yuyama et al., 2005), e as adubações foram realizadas conforme resultados da análise de solo.

Durante cinco ciclos de produção do palmito, foram avaliados os seguintes caracteres: massa da base (TB), em g; massa líquida total (TL), em g; produtividade do palmito de pupunheira de primeira qualidade (T1), em g; produtividade do palmito de segunda qualidade (T2), em g; número de plantas por parcela (PP); número de toletes (NT); e diâmetro do palmito (D), em mm. Estes dados se referem aos cinco cortes do palmito, o primeiro aos 27 meses após o plantio das mudas, e os demais a cada 12 meses.

O diagnóstico de multicolinearidade foi realizado inicialmente para identificar possíveis relações lineares entre linhas ou colunas da matriz de correlação residual (Cruz \& Carneiro, 2003). Estes autores afirmam que, se houver multicolinearidade em níveis de moderados a severos, as estimativas dos parâmetros podem assumir valores absurdos ou sem nenhuma coerência com o fenômeno biológico estudado. No presente trabalho, foram detectados problemas com a multicolinearidade indicada como severa, para os caracteres massa líquida total do palmito e número de toletes, que foi excluída das análises posteriores.

Em seguida, realizou-se a análise de variância, com o seguinte modelo: $Y_{i j}=m+g_{i}+b_{j}+\varepsilon_{i j}$, em que: $Y_{i j}$ é a observação na i-ésima família; $m$ é a média geral; $g_{i}$ é o efeito da i-ésima família; i $=1,2 \ldots$ g; bj é o efeito do i-ésimo bloco; $\mathrm{j}=1,2 \ldots \mathrm{r} ; \varepsilon_{\mathrm{ij}}$ é o erro aleatório.

Os valores médios foram ordenados segundo o teste de agrupamento de Scott-Knott, a 5\% de probabilidade. Para estimar a divergência genética entre as progênies utilizou-se a distância generalizada de Mahalanobis $\left(\mathrm{D}^{2}\right)$ como medida de dissimilaridade e o método de otimização de Tocher (Rao, 1952) para a delimitação dos agrupamentos das progênies. Para quantificar a percentagem de contribuição relativa dos caracteres à diversidade genética, aplicou-se a análise de variáveis canônicas. Todos os procedimentos estatísticos foram realizados pelo programa Genes (Cruz, 2006), de acordo com os modelos descritos por Cruz et al. (2004).

\section{Resultados e Discussão}

Houve diferenças significativas nas médias das progênies em todas as variáveis, exceto quanto ao diâmetro do palmito (Tabela 1), o que é indicativo da presença de variabilidade entre as progênies e de possibilidade de ganhos por seleção (Karasawa et al., 2005). O coeficiente de variação (CV) das variáveis agronômicas - massa do palmito de primeira e de segunda e plantas por parcela - foi maior do que $30 \%$ e, quanto à massa da base do palmito, foi maior do que $27 \%$, tendo sido, portanto, satisfatórios, uma vez que foram detectadas diferenças significativas para a maioria das variáveis avaliadas entre as progênies.

O caráter diâmetro do palmito não apresentou diferença significativa entre as progênies e variou de 24,75 a 32,15 mm (Tabela 2). Bergo et al. (2004) também não observaram diferença significativa para este caráter no primeiro ano de produção de palmito. No entanto, Farias Neto (1999) observou variação significativa de $13,2 \%$ no diâmetro do palmito, com valores de 17 a $38 \mathrm{~mm}$ entre famílias de pupunheira. Yuyama et al. (2005) afirmaram que o diâmetro do palmito tende a diminuir com o alto adensamento do plantio. Contudo, apesar de haver preferência por palmitos de menor diâmetro (Clement \& Bovi, 2000; Flori et al., 2001), palmitos de maior diâmetro também têm demanda em determinados segmentos do mercado consumidor.

O teste de médias dividiu as variáveis em dois grupos, com exceção do diâmetro do palmito (Tabela 2). Yokomizo \& Farias Neto (2003) também observaram a formação de dois grupos, pelo mesmo método para variáveis morfoagronômicas de pupunheiras no Amapá, e recomendaram, conforme o agrupamento, que progênies de menor desempenho sejam descartadas apenas se não apresentarem outras características importantes para futuros processos de melhoramento, como resistência a pragas e doenças, precocidade e melhor perfilhamento.

Quanto à massa da base do palmito, o grupo de maior média abrangeu $52 \%$ das progênies, em que 
as progênies $3,38,39,54,60,75$ e 94 apresentaram massa acima de $6.000 \mathrm{~g}$, na soma dos cinco cortes efetuados. Quanto à variável massa do palmito de primeira, as progênies $3,22,38,55,81$ e 92, que representaram $48 \%$ do grupo de maior média, ficaram acima de $2.700 \mathrm{~g}$, valor $30 \%$ acima da média geral (Tabela 1). Quanto à massa de palmito de segunda, o grupo de maior média conteve $43 \%$ das progênies com maiores médias, em que as progênies 21, 22, 29, $38,39,54$ e 60 obtiveram valores acima de $1.900 \mathrm{~g}$. O peso do palmito é importante no melhoramento, por ser o principal caráter ligado à produção; assim, sua comercialização se dá como picadinho, rodela ou tolete, com o aproveitamento máximo do produto (Kalil Filho et al., 2010). A parte nobre do palmito (palmito de primeira), comercializado em toletes, é a de maior valor comercial (Bellegard et al., 2005) e de grande interesse no processo de seleção quanto aos ganhos de produtividade. Bergo et al. (2004), que estudaram pupunheiras para produção de palmito no Acre, observaram médias de 501,7 e 215,5 g, quanto à massa da base do palmito e palmito de primeira, respectivamente, valores considerados acima da produtividade média regional.

Quanto ao número de plantas por parcela, 46\% das progênies ficaram no grupo de maior média, em que as progênies 3,21, 39, 54, 60, 81 e 92 apresentaram valores acima de 17 plantas, com média de 3,4 plantas por parcela por ano. Na seleção quanto aos ganhos em produtividade, deve-se considerar o perfilhamento como indicador de vigor para o melhoramento genético da espécie, uma vez que o maior rendimento de palmitos de primeira ou toletes é apresentado nos perfilhos (Kalil Filho et al., 2010). Clement (1997) cita esta característica como uma das principais, entre aquelas que definem um ideótipo de pupunheira para produção de palmito, em que a regeneração de cada touceira, após cada colheita, depende de uma produção numerosa e contínua de perfilhos com 4 ou mais estipes por ano. Como houve a formação de somente dois grupos para todas as características pelo teste de Scott-Knott, houve dificuldade de selecionar as melhores progênies com base somente nas médias destes grupos. Por isso, utilizou-se o agrupamento de Tocher, pois, para se obter ganho genético necessita-se de variabilidade e produção elevada. Essas informações associadas ao teste de médias podem ser utilizadas como critério de seleção.

A dissimilaridade entre os pares de progênies concentrou $65,75 \%$ dos pares nas menores distâncias $(0,09$ a 5,06$)$, tendo sido a maior distância $(20,36)$ entre os pares 21 e 80 , e a menor $(0,09)$ entre as progênies 52 e 62 . Isto é indicativo de que as progênies são muito

Tabela 1. Análise de variância da massa da base do palmito (TB), massa do palmito de primeira (T1), massa do palmito de segunda (T2), diâmetro do palmito (D), e plantas por parcela (PP) de 100 progênies de meios-irmãos de pupunheira.

\begin{tabular}{|c|c|c|c|c|c|c|}
\hline \multirow[t]{2}{*}{ Fonte de variação } & \multicolumn{6}{|c|}{ Quadrados médios } \\
\hline & GL & TB & $\mathrm{T} 1$ & $\mathrm{~T} 2$ & $\mathrm{D}$ & $\mathrm{PP}$ \\
\hline Blocos & 2 & 3.991 .311 & 1.768 .878 & 973.728 & 6,53 & 2,40 \\
\hline Tratamentos & 99 & $2.859 .704 *$ & $632.987 *$ & $326.976^{*}$ & $7,09^{\mathrm{ns}}$ & $26,74 *$ \\
\hline Resíduo & 198 & 1.431 .457 & 404.773 & 170.879 & 8,14 & 12,42 \\
\hline Total & 299 & & & & & \\
\hline Média & & $4.393,45$ & $2.090,08$ & $1.346,11$ & 28,30 & 11,59 \\
\hline CV $(\%)$ & & 27,23 & 30,44 & 30,71 & 10,08 & 30,41 \\
\hline
\end{tabular}

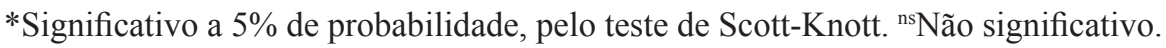

Tabela 2. Médias, mínimas e máximas observadas no agrupamento pelo teste de Scott-Knott de 100 progênies de meios-irmãos de pupunheira, quanto à massa da base do palmito (TB), massa do palmito de primeira (T1), massa do palmito de segunda (T2), diâmetro do palmito (D) e plantas por parcela (PP), além de percentagem de progênies por grupo.

\begin{tabular}{|c|c|c|c|c|c|c|c|c|c|c|c|}
\hline \multicolumn{2}{|c|}{ Scott-Knott } & \multirow{2}{*}{$\frac{\mathrm{TB}(\mathrm{g})}{1.872,87}$} & \multirow[t]{2}{*}{$\%$} & \multirow{2}{*}{$\frac{\mathrm{T} 1(\mathrm{~g})}{942,80}$} & \multirow[t]{2}{*}{$\%$} & \multirow{2}{*}{$\frac{\mathrm{T} 2(\mathrm{~g})}{494,77}$} & \multirow[t]{2}{*}{$\%$} & \multirow{2}{*}{$\frac{\mathrm{D}(\mathrm{mm})}{-}$} & \multirow[t]{2}{*}{$\%$} & \multirow{2}{*}{$\begin{array}{c}\mathrm{PP} \\
5,33\end{array}$} & \multirow[t]{2}{*}{$\%$} \\
\hline $\bar{B}$ & mínimo & & & & & & & & & & \\
\hline & máximo & $4.345,67$ & 48 & $2.094,97$ & 52 & $1.377,83$ & 57 & - & & 11,67 & 54 \\
\hline \multirow[t]{2}{*}{ A } & mínimo & $4.370,90$ & & $2.114,97$ & & $1.410,97$ & & 24,75 & 100 & 12,00 & \\
\hline & máximo & $6.315,73$ & 52 & $3.219,57$ & 48 & $2.081,17$ & 43 & 32,15 & & 17,67 & 46 \\
\hline
\end{tabular}

A, agrupamento de maior média; B, agrupamento de menor média; (-) valores ausentes. 
semelhantes morfologicamente quanto às variáveis agronômicas analisadas.

O método de Tocher apresenta a distância média dentro dos grupos sempre menor do que a distância média entre os grupos (Vasconcelos et al., 2007), portanto haverá mais homogeneidade entre os acessos de um mesmo grupo do que entre os acessos de diferentes grupos.

Por meio do método de agrupamento de otimização de Tocher, foram formados 26 grupos distintos (Tabela 3). O grupo 1 foi o que reuniu o maior número de progênies (22). Em geral, grande variabilidade foi observada em relação à formação de grupos, o que decorre da divergência entre as progênies. Provavelmente, essa diversidade é consequência da multiplicidade de origens e da segregação do material, ocorrida durante os cultivos estabelecidos ao longo dos anos, em diferentes localidades. Com a finalidade de se obter ganho genético, nos ciclos subsequentes de melhoramento, é recomendável a seleção de progênies que se encontrem em grupos de maior divergência e que tenham maior desempenho produtivo. Os grupos de melhor desempenho produtivo apresentaram, em média, variação abaixo de $10 \%$, nos grupos formados com dois ou mais indivíduos, e o diâmetro do palmito apresentou cerca de 4\% de variação. Farias Neto (1999) observou variação genética significativa entre famílias de pupunheiras no Amapá, em todos os caracteres avaliados.

Os grupos de melhor desempenho pelo método de Tocher foram G3, G5, G11, G12, G17, G18, G21 e G22, com valores das variáveis agronômicas 33\% acima da média geral do experimento. As progênies com os maiores valores de massa de palmito de primeira foram a 22 , a 55 e a 38 , dos grupos G17 e G18, com média de massa de palmito de primeira $43 \%$ maior do que a média geral dos grupos, tendo alcançado até $3.168 \mathrm{~g}$ na soma dos cinco cortes. O número de plantas por parcela foi maior para os grupos G5 e G22, com $42 \%$ acima da média dos grupos, com mais de 17 plantas por parcela nos cinco cortes. Estas variáveis,

Tabela 3. Média do agrupamento de 100 progênies de meios irmãos de pupunheira pelo método de otimização de Tocher, baseado na distância generalizada de Mahalanobis, quanto à massa da base do palmito (TB), massa do palmito de primeira (T1), massa do palmito de segunda (T2), diâmetro do palmito (D) e plantas por parcela (PP), além de características médias dos grupos.

\begin{tabular}{|c|c|c|c|c|c|c|}
\hline Grupo & Progênies & TB $(\mathrm{g})$ & $\mathrm{T} 1(\mathrm{~g})$ & $\mathrm{T} 2(\mathrm{~g})$ & $\mathrm{D}(\mathrm{mm})$ & PP \\
\hline G1 & $7,10,16,17,24,28,31,33,42,48,50,52,56,58,62,64,74,82,89,90,97,98$ & 3522,21 & 1793,63 & 1109,30 & 28,25 & 9,41 \\
\hline G2 & $11,26,37,68,69,73,76,83,84,87,93$ & 4695,58 & 2005,56 & 1320,38 & 27,18 & 11,56 \\
\hline G3 & $2,6,14,15,29,40,44,81,91,92$ & 5111,73 & 2496,75 & 1633,69 & 27,73 & 15,40 \\
\hline G4 & $1,23,35,70,100$ & 4317,11 & 2205,43 & 1607,14 & 28,14 & 12,93 \\
\hline G5 & $30,54,60$ & 5904,84 & 2455,06 & 1916,32 & 28,22 & 17,00 \\
\hline G6 & $20,32,34,36,53,57,59,72$ & 4989,75 & 2386,09 & 1570,70 & 29,60 & 12,50 \\
\hline G7 & $13,47,51,66,79,95$ & 3696,34 & 1603,85 & 955,69 & 29,37 & 8,28 \\
\hline G8 & $41,43,63,77,88$ & 4319,55 & 2394,29 & 1220,87 & 29,26 & 10,93 \\
\hline G9 & 18,86 & 3553,45 & 1672,05 & 1144,97 & 31,52 & 8,50 \\
\hline G10 & $46,61,67,78$ & 3884,13 & 2027,19 & 1347,80 & 27,98 & 9,42 \\
\hline G11 & 3,94 & 6113,88 & 2673,23 & 1667,95 & 26,68 & 16,83 \\
\hline G12 & 39,75 & 6239,53 & 2641,17 & 1990,00 & 25,67 & 16,33 \\
\hline G13 & 45,96 & 3806,77 & 1974,68 & 1040,20 & 30,65 & 10,50 \\
\hline G14 & 4,8 & 3147,25 & 1320,47 & 918,43 & 28,11 & 9,17 \\
\hline G15 & 49,80 & 5010,30 & 2110,77 & 1158,75 & 31,34 & 9,50 \\
\hline G16 & 9,85 & 3162,65 & 1246,05 & 1096,98 & 27,23 & 7,67 \\
\hline G17 & $22,25,55$ & 5583,73 & 3167,58 & 1771,12 & 27,74 & 15,33 \\
\hline G18 & 38 & 6315,73 & 2983,17 & 1931,70 & 28,04 & 15,33 \\
\hline G19 & 12 & 5762,90 & 2618,17 & 1493,63 & 26,05 & 14,33 \\
\hline G20 & 99 & 5050,57 & 2340,83 & 1308,57 & 30,17 & 12,67 \\
\hline G21 & 5 & 5348,60 & 2545,93 & 1546,90 & 31,12 & 15,33 \\
\hline G22 & 21 & 5317,60 & 2693,37 & 2024,63 & 27,40 & 17,33 \\
\hline G23 & 27 & 4507,10 & 1898,47 & 1492,77 & 28,72 & 12,67 \\
\hline G24 & 65 & 5369,10 & 2235,27 & 1526,53 & 27,98 & 10,67 \\
\hline G25 & 71 & 3082,50 & 1459,63 & 1048,17 & 25,16 & 10,00 \\
\hline G26 & 19 & 1872,87 & 942,80 & 494,77 & 26,01 & 5,33 \\
\hline
\end{tabular}


número de plantas por parcelas e massa de palmito de primeira, são as mais representativas na busca de progênies superiores de pupunheira para a produção de palmito. Por representar a capacidade de regeneração da touceira, após a colheita, a primeira variável é de grande importância para a longevidade do plantio, o que está diretamente relacionado à sustentabilidade econômica do cultivo. A produção de toletes ou palmito de primeira é a segunda variável e é a parte de maior valor comercial, portanto, é de grande interesse para o processo de seleção quanto aos ganhos de produtividade (Clement \& Bovi, 2000).

Com a análise de variáveis canônicas, observou-se uma possível estruturação de grupos, semelhante ao método de Tocher, que resultou em cinco autovalores ou variáveis canônicas, dos quais as três primeiras somaram $75,12 \%$ da variância original dos dados. A variável planta por parcela é a mais importante na discriminação das progênies na primeira variável canônica (VC1) $(35,77 \%)$, seguida pela massa do palmito de segunda, indiretamente relacionada à massa do palmito de primeira (Tabela 4). Estes valores são chamados autovalores e são obtidos a partir dos dados originais, o que resume as propriedades essenciais dentro do conjunto de dados (Cruz et al., 2004).

$\mathrm{Na}$ segunda variável canônica (VC2) (22,93\%), a massa do palmito de segunda, seguida do número de plantas por parcela, indiretamente relacionadas à massa de base do palmito são as variáveis mais importantes. $\mathrm{Na}$ terceira variável canônica (VC3), a massa do palmito de primeira é a mais importante (Tabela 4).

Tabela 4. Autovalores e autovetores das variáveis canônicas (VC) dos dados originais das características agronômicas massa da base do palmito (TB), massa do palmito de primeira (T1), massa do palmito de segunda (T2), diâmetro do palmito (D) e plantas por parcela (PP) de 100 progênies de pupunheiras.

\begin{tabular}{lccc}
\hline & VC1 & VC 2 & VC 3 \\
\hline Autovalor & 0,7925 & 0,580 & 0,3638 \\
Variância (\%) & 35,77 & 22,93 & 16,42 \\
Variância acumulada (\%) & 35,77 & 58,70 & 75,12 \\
\hline Variáveis & \multicolumn{3}{c}{ Autovetores } \\
\hline TB & 0,1173 & $-2,1868$ & $-0,5862$ \\
T1 & $-0,5939$ & 0,1895 & 1,4073 \\
T2 & 0,4119 & 0,9747 & $-0,9310$ \\
D & 0,2700 & 0,0744 & 0,4992 \\
PP & 1,0490 & 0,8981 & 0,4335 \\
\hline
\end{tabular}

O diâmetro do palmito apresentou o menor peso, em relação ao restante das variáveis agronômicas, nas três variáveis canônicas, e atribuiu pouco peso à formação de grupos. No entanto, esta característica na industrialização do palmito tem influência significativa na padronização do tempo de cozimento, no equilíbrio químico da conserva e na acomodação do palmito dentro do recipiente (Bellegard et al., 2005). As variáveis plantas por parcela (que determinam o potencial de perfilhamento das plantas), massa do palmito de segunda e massa de base do palmito (determinadas pelas variáveis canônicas 1 e 2 , respectivamente) direcionaram a formação de um grupo com indivíduos superiores. Bergo et al. (2004) relataram o número de perfilhos e a massa da base do palmito como caracteres indicadores de ganho de produção, o que resulta da formação de grupos das progênies.

As progênies 3, 5, 15, 21, 29, 30, 34, 39, 40, 44, $54,60,75,81,91,92,94$ e 100 foram agrupadas com base nas seguintes variáveis agronômicas: número de plantas por parcela, massa da base do palmito e massa do palmito de segunda. Este resultado foi semelhante ao da formação de alguns grupos de melhor desempenho pelo método de Tocher, em que se destacam os grupos G3, G5, G11 e G12 (Tabela 3). Em razão da sua estruturação constante, a formação de grupos coincidentes, na utilização de métodos complementares para caracteres morfoagronômicos, gera maior confiabilidade nos resultados (Martel et al., 2003; Sudré et al., 2005; Oliveira et al., 2007). Assim, com base nestas informações, é possível relacionar as progênies pertencentes aos grupos G3, G5, G11 e G12 como de maior potencial para a seleção e os ganhos de produtividade de palmito.

\section{Conclusões}

1. As progênies das pupunheiras apresentam variação quanto aos caracteres de palmito avaliados, exceto quanto ao diâmetro do palmito.

2. As progênies apresentam forte divergência, com formação de 26 grupos pelo método de Tocher, em que se destacam os grupos G3, G5, G11 e G12 de melhor desempenho.

3. Os grupos de progênies de melhor desempenho apresentam potencial para a seleção quanto ao aumento da produtividade do palmito, em programas de melhoramento genético da pupunheira.

Pesq. agropec. bras., Brasília, v.48, n.5, p.496-503, maio 2013 DOI: $10.1590 / \mathrm{S} 0100-204 \mathrm{X} 2013000500005$ 


\section{Agradecimentos}

À Empresa Brasileira de Pesquisa Agropecuária (Embrapa), pelo apoio financeiro.

\section{Referências}

ARAÚJO, M. de C.; RODRIGUES, D.P.; ASTOLFI FILHO, S.; CLEMENT, C.R. Genetic variability in the peach palm genebank with RAPD markers. Crop Breeding and Applied Biotechnology, v.10, p.211-217, 2010. DOI: 10.1590/S198470332010000300005 .

BATAGIN-PIOTTO, K.D.; ALMEIDA, C.V. de; PIOTTO, F.A.; ALMEIDA, M. de. Anatomical analysis of peach palm (Bactris gasipaes) leaves cultivated in vitro, ex vitro and in vivo. Brazilian Journal of Botany, v.35, p.71-78, 2012. DOI: 10.1590/ S1806-99592012000100008.

BELLEGARD, C.R.G.; RAUPP, D. da S.; CHAIMSOHN, F.P.; BORSATO, A.V. Avaliação de procedimentos de acidificação de conservas de palmito foliar de pupunha (Bactris gasipaes). Acta Scientiarum. Agronomy, v.27, p.247-254, 2005. DOI: 10.4025/ actasciagron.v27i2.1842.

BERGO, C.L.; MENDONÇA, H.A.; LEDO, F.J.S. Estimativa de parâmetros genéticos e fenotípicos em progênies de meioirmãos de pupunheira (Bactris gasipaes Kunth, Palmae) na Amazônia Ocidental. Revista de Ciências Agrárias, n.42, p.127-142, 2004.

CLEMENT, C.R. Domestication of the pejibaye palm (Bactris gasipaes): past and present. Advances Economic Botany, v.6, p.155-174, 1988.

CLEMENT, C.R. Pupunha: recursos genéticos para a produção de palmito. Horticultura Brasileira, v.15, p.186-191, 1997. Suplemento.

CLEMENT, C.R.; BOVI, M.L.A. Padronização de medidas de crescimento e produção em experimentos com pupunheira para palmito. Acta Amazonica, v.30, p.349-362, 2000.

CRUZ, C.D. Programa Genes: estatística experimental e matrizes. Viçosa: Ed. UFV, 2006. 285p.

CRUZ, C.D.; CARNEIRO, P.C.S. Modelos biométricos aplicados ao melhoramento genético. Viçosa: Ed. UFV, 2003. 579p.

CRUZ, C.D.; REGAZZI, A.J.; CARNEIRO, P.C.S. Modelos biométricos aplicados ao melhoramento genético. Viçosa: Ed. UFV, 2004. 480p.

FARIAS NETO, J.T. de. Estimativas de parâmetros genéticos em progênies de meioirmãos de pupunheira. Boletim de Pesquisa Florestal, n.39, p.109-117, 1999.

FLORI, J.E.; RESENDE, G.M.; DRUMOND, M.A. Rendimento do palmito de pupunha em função da densidade de plantio, diâmetro de corte e manejo dos perfilhos, no Vale do São Francisco. Horticultura Brasileira, v.19, p.140-143, 2001. DOI: 10.1590/ S0102-05362001000200009.

GALDINO, N.O.; CLEMENT, E. Palmito de pupunha (Bactris gasipaes Kunth), composição mineral e cinética de enzimas oxidativas. Ciência e Tecnologia de Alimentos, v.28, p.540-544, 2008. DOI: 10.1590/S0101-20612008000300006.

INSTITUTO BRASILEIRO DE GEOGRAFIA E ESTATÍSTICA. Banco de dados agregados. 2011. Disponível em: $<$ http://www. sidra.ibge.gov.br/bda/default.asp? $\mathrm{z}=\mathrm{t} \& \mathrm{o}=1 \& \mathrm{i}=\mathrm{P}>$. Acesso em: 13 jun. 2013.

KALIL FILHO, A.N.; CLEMENT, C.R.; RESENDE, M.D.V. de; FARIAS NETO, J.T. de; BERGO, C.L.; YOKOMIZO, G.K.I.; KAMINSKI, P.E.; YUYAMA, K.; MODOLO, V.A. Programa de melhoramento genético de pupunha na Embrapa, IAC e Inpa. Colombo: Embrapa Florestas, 2010. 34p. (Embrapa Florestas. Documentos, 205).

KARASAWA, M.; RODRIGUES, R.; SUDRÉ, C.P.; SILVA, M.P. da; RIVA, E.M.; AMARAL JÚNIOR, A.T. do. Aplicação de métodos de agrupamento na quantificação da divergência genética entre acessos de tomateiro. Horticultura Brasileira, v.23, p.1000-1005, 2005. DOI: 10.1590/S0102-05362005000400028.

MARTEL, J.H.I.; FERRAUDO, A.S.; MÔRO, J.R.; PERECIN, D. Estatística multivariada na discriminação de raças amazônicas de pupunheiras (Bactris gasipaes Kunth) em Manaus (Brasil). Revista Brasileira de Fruticultura, v.25, p.115-118, 2003. DOI: 10.1590/S0100-29452003000100033.

OLIVEIRA, M. do S.P. de; FERREIRA, D.F.; SANTOS, J.B. dos. Divergência genética entre acessos de açaizeiro fundamentada em descritores morfoagronômicos. Pesquisa Agropecuária Brasileira, v.42, p.501-506, 2007. DOI: 10.1590/ S0100-204X2007000400007.

RAO, C.R. Advanced statistical methods in biometric research. New York: John Wiley, 1952. 390p.

RIBEIRO, F.S. de C.; SOUZA, V.A.B. de; LOPES, A.C. de A. Diversidade genética em castanheira-do-gurgueia (Dipterix lacunifera Ducke) com base em características físicas e químiconutricionais do fruto. Revista Brasileira de Fruticultura, v.34, p.190-199, 2012. DOI: 10.1590/S0100-29452012000100026.

SANTOS, H.G. dos; JACOMINE, P.K.T.; ANJOS, L.H.C. dos; OLIVEIRA, V.A. de; OLIVEIRA, J.B. de; COELHO, M.R.; LUMBRERAS, J.F.; CUNHA, T.J.F. (Ed.). Sistema brasileiro de classificação de solos. 2.ed. Rio de janeiro: Embrapa Solos, 2006. $306 \mathrm{p}$.

SILVA, D.F.P.; SIQUEIRA, D.L. de; ROCHA, A.; SALOMÃO, L.C.C.; MATIAS, R.G.P.; STRUIVINH, T.B. Diversidade genética entre cultivares de mangueiras, baseada em caracteres de qualidade dos frutos. Ceres, v.59, p.225-232, 2012. DOI: 10.1590/S0034-737X2012000200011.

SOUSA, N.R.; RODRIGUES, D.P.; CLEMENT, C.R.; NAGAO, E.O.; ASTOLFI-FILHO, S. Discriminação de raças primitivas de pupunha (Bactris gasipaes) na Amazônia por meio de marcadores moleculares (RAPDS). Acta Amazonica, v.31, p.539-545, 2001.

SUDRÉ, C.P.; RODRIGUES, R.; RIVA, E.M.; KARASAWA, M.; AMARAL JÚNIOR, A.T. do. Divergência genética entre acessos de pimenta e pimentão utilizando técnicas multivariadas. Horticultura Brasileira, v.23, p.22-27, 2005. DOI: 10.1590/ S0102-05362005000100005. 
VASCONCELOS, E.S. de; CRUZ, C.D.; BHERING, L.L.; RESENDE JÚNIOR, M.F.R. Método alternativo para análise de agrupamento. Pesquisa Agropecuária Brasileira, v.42, p.1421-1428, 2007. DOI: 10.1590/ S0100-204X2007001000008.

YOKOMIZO, G.K.I.; FARIAS NETO, J.T. de. Caracterização fenotípica e genotípica de progênies de pupunheira para palmito.
Pesquisa Agropecuária Brasileira, v.38, p.67-72, 2003. DOI: 10.1590/S0100-204X2003000100009.

YUYAMA, K.; CHÁVEZ F., W.B.; PEREIRA, B.G.; SILVA, I.SA. Efeito da densidade de plantas e da adubação NPK na produção inicial de palmito de pupunheira. Revista Brasileira de Ciência do Solo, v.29, p.373-378, 2005. DOI: 10.1590/ S0100-06832005000300007.

Recebido em 16 de janeiro de 2013 e aprovado em 26 de abril de 2013 